\title{
Fungal Coagulant for Reduction of Water Turbidity
}

\author{
Abdullah Al-Mamun ${ }^{1}$, Jebunnessa ${ }^{2}$, Md. Zahangir Alam³ and Raha Ahmad Raus ${ }^{4}$
}

\begin{abstract}
Turbidity from raw water is, usually, removed from by adding chemical coagulants. These chemicals are hazardous to human body and not much environmentally friendly. Therefore, this study was intended to discover microbial coagulant which would be a new replacement for the chemical coagulants. There are potential microorganisms, those can produce bioactive compounds, which can lead to different charges and surface properties. As such, the main goal of this project was to reduce turbidity of river water using natural coagulant. The discovered microbial coagulant showed promising results which can be considered as safe and environmentally friendly as compared to the conventional chemical coagulants. Thus far, a potential fungal strain is successfully identified which could reduce turbidity of water from 900 NTU to 54 NTU. It is expected that further optimization of the process parameters will help reduce the turbidity of the water. However, the full-scale application of the findings and the economic evaluation of the new coagulant is not determined yet.
\end{abstract}

Keywords - Coagulation, Fungus, Turbidity, Water.

\section{INTRODUCTION}

$\mathrm{T}$ HE high turbidity and suspended solids are the most common challenges faced by many rivers in the world. Use of microbial coagulant to improve the aesthetic quality of river water is not found yet in the literature. Isolated filamentous fungi and yeast from river water have shown good entrapment potentiality to reduce turbidity from river water and kaolin clay suspension. The screened microbial coagulant has good ability to reduce colloidal particles and enhance sedimentation of kaolin suspension. Further research will help ascertain the microbial strains, which are capable to reduced turbidity and enhance aesthetic quality of river water.

Traditionally, turbidity of water is reduced by various processes such as coagulation, flocculation, sedimentation, followed by sand filtration and disinfection [1]. It is important to study the coagulation and flocculation mechanism for us to understand the role of coagulants in water and wastewater treatment and to improve the aesthetic quality of water. Generally, coagulants help aggregation of colloidal and other particles by bridging among the particles and neutralizing particle charges [2]. It is reported that cation based bridges between the particles and coagulant chains primarily help form flocs and flocculation process [3, 4].

Due to good efficiency, no secondary pollution, and other benefits, microbial coagulants have great potentials for vast

Abdullah Al Mamun ${ }^{1}$ is with the International Islamic University Malaysia, IIUM.

The other authors are also from the same university. application [2]. Therefore, filamentous fungi have attracted biotechnological attention to treat water and wastewater due to their turbidity removal ability [5, 6]. Fungal coagulants are reported to be used for the recovery of suspended solids (SS) from water and wastewater. On the other hand, it is difficult for the synthetic coagulants to be degraded easily in the nature $[7,8]$. As a result, the chemical coagulants are reported to have various detrimental effects on the environment [9].

The microbial product can be used as commercial coagulant for removal of turbidity and suspended solids (SS) from river water which would be a new replacement of the chemical coagulants. The new potential microbial coagulant (product) can be patented for commercial and other benefits. As such, there is huge commercial and academic potential of the microbial coagulant for the water resources management. A pilot-scale study and detail characterization of the fungal coagulant will provide new knowledge and opportunities in developing eco-friendly and safe microbial coagulants which will be more environmentally friendly compared to the chemical coagulants used.

\section{II.METHODOLOGY}

In this study potato dextrose agar (PDA) was used as per the manufacturer's instructions. All flasks, funnels, filter papers and distil water were sterilized before use. $\mathrm{pH}$ of the PDA solution was adjusted to $5.8 \pm 2$ and then incubated at $32 \pm 2{ }^{\circ} \mathrm{C}$ for the required days. All samples were stored at $4{ }^{\circ} \mathrm{C}$ for further use. The fungal strains were sub-cultured once in a month. The fungi were isolated from river water using the spread plate technique [10]. One $\mathrm{ml}$ raw river water sample was dissolved in $9 \mathrm{ml}$ sterilized distilled water. The water samples were collected from the nearby river called Sg. Pusu, which flows through the IIUM Gombak Campus. The water samples were diluted from $10^{-1}$ to $10^{-5}$. The isolated samples were inoculated on the PDA plates prepared in the laboratory. Then the inoculated plates were incubated at ambient temperature $\left(30 \pm 2{ }^{\circ} \mathrm{C}\right)$ for 5-7 days. Formation of the colonies was clearly visible after the incubation for 5 to 7 days. The fungal colonies were aseptically picked up and transferred to fresh sterile PDA plates to obtain new pure cultures. The pure cultures on PDA plates were grown at $30 \pm$ $2{ }^{\circ} \mathrm{C}$ for the same durations and then stored at $4{ }^{\circ} \mathrm{C}$ for future usage.

For the subsequent experiments, the inoculum of spore suspension was used for spore producing while the mycelial suspension was used for basidiomycete. The culture plates were transferred into Erlenmeyer flask $(250 \mathrm{ml})$ containing $100 \mathrm{ml}$ of sterile distilled water. A rotary shaker with $150 \mathrm{rpm}$ 
was used for $24 \mathrm{hr}$ for the mixing purpose. The suspended solids were filtered by Whatman filter paper No. 1 and the filtrate was used as inoculum. The spore numbers were measured by Hemocytometer. Typically the spore numbers varied between 1 and $2.5 \times 10^{8}$ spore $/ \mathrm{ml}$ ).

The 7-day old cultures were used for mycelial suspension. The mycelia in plates were washed for three times with $100 \mathrm{ml}$ of sterile distilled water and then poured into a $100 \mathrm{ml}$ flask to use as final inoculum. The fungus for fermentation was grown in $250 \mathrm{ml}$ Erlenmeyer flasks with medium containing $0.5 \%$ malt extract and mixed with 1 litter distilled water. The media was sterilized by autoclaving it at $121^{\circ} \mathrm{C}$ for 15 minutes. Then inoculated $2 \%(\mathrm{v} / \mathrm{v})$ fungal inoculum into liquid media. The liquid culture was incubated in a rotary shaker with $150 \mathrm{rpm}$ at room temperature for 7 days. Initial $\mathrm{pH}$ of the culture was adjusted to $7.00 \pm 0.1$ using $1 \mathrm{M} \mathrm{NaOH}$ or $2 \mathrm{M} \mathrm{HCl}$ solution. All fungus was harvested after 7 days of cultivation time, and the biomass was separated from the supernatant by Whatman No.1 filter paper. Then the supernatant was stored at $4{ }^{\circ} \mathrm{C}$ for further use. A flowchart showing the main activities used in the methodology is shown in Fig. 1.

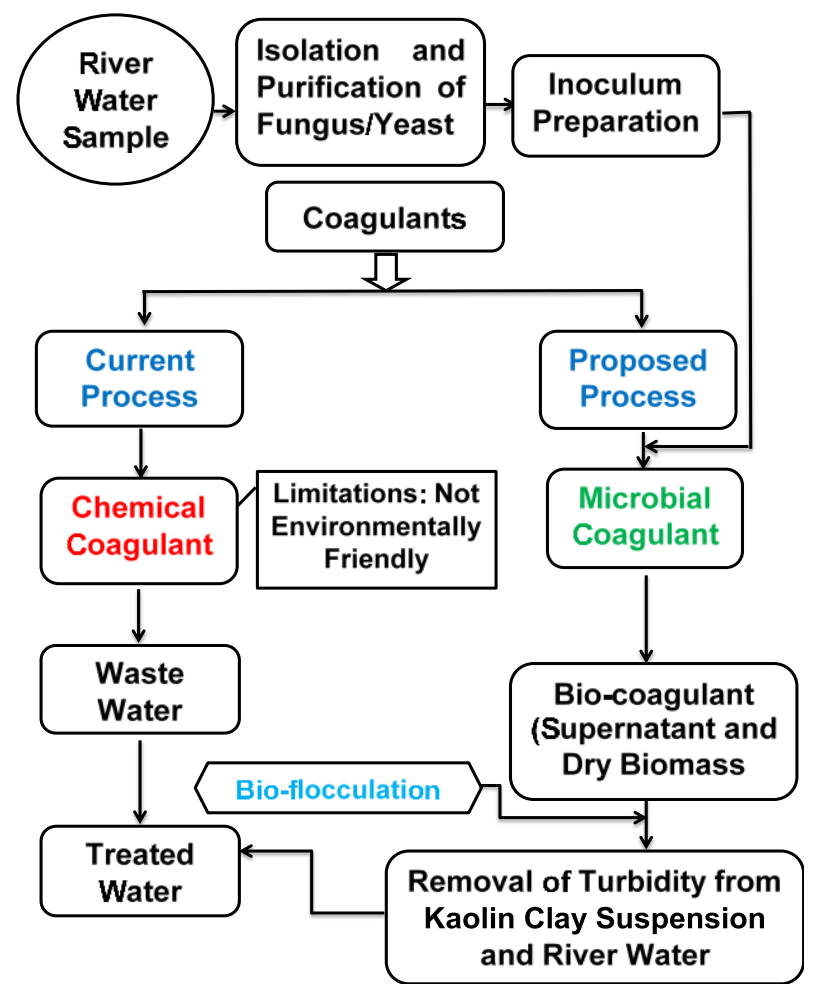

Fig. 1: Methodology used in the Study

\section{RESULTS AND DISCUSSION}

\section{A. Screening for Fungal Coagulant}

Six different strains of filamentous fungi (Fig. 2 to 4), isolated from river water were tested on Kaolin suspension and river water with initial turbidity of $900 \pm 10$ NTU. The result showed that RWF-5 and RWF-6 effectively reduced the colloidal particles from Kaolin suspension and river water. The turbidity removal was significantly decreased from 900 NTU to 54 NTU (95\%) by the biocoagulant of RWF-5 and
200 NTU by the RWF-6. Pu et al. (2014) [11] observed that Rhizopus sp., strain M9 and M17, showed good turbidity removal rates of $54 \%$ and $92 \%$ from the potato starch wastewater, respectively. Similar results were obtained for Aspergillus flavus due to the presence of hydroxyl, amide, carboxyl and methoxyl groups which are suitable functional groups for the coagulation process [12].

The maximum coagulating rate observed at 40 mins was 95\%. Deng et al. (2003) [13] reported that the fungal coagulant produced by $B$. mucilaginosus was able to reduce turbidity from kaolin suspensions without cations.

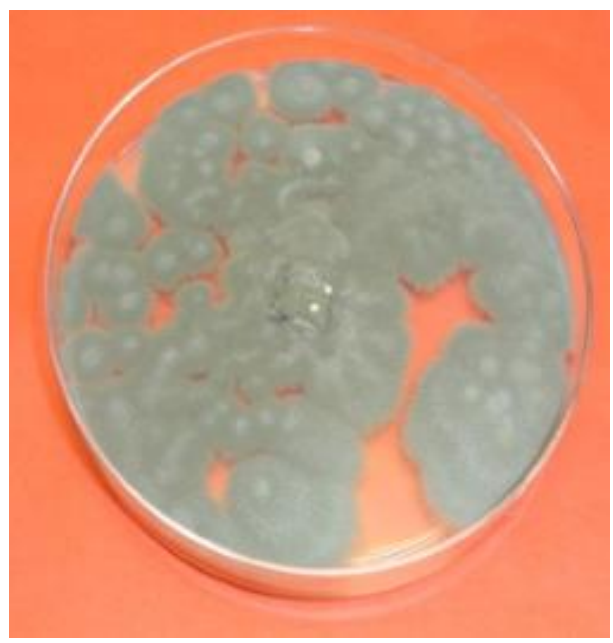

Fig. 2: Screening of Fungus

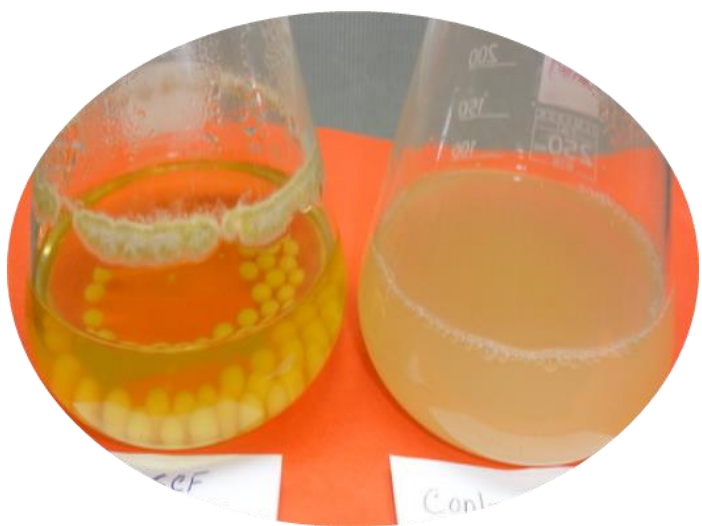

Fig. 3: Preparation of Inoculum and Formation of Ball

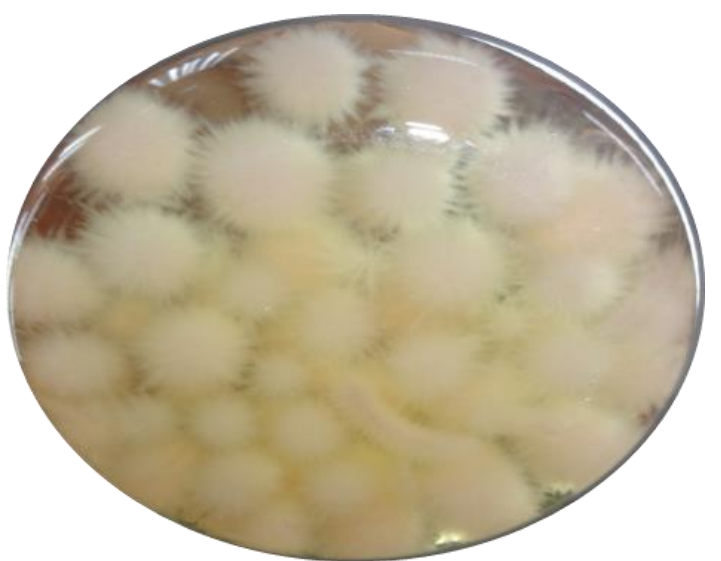

Fig. 4: Enlarged View of the Fungal Ball 
Filamentous fungi showed good entrapment capability to coagulate colloidal particles from kaolin suspension and river water. Fungal supernatant had reduced $94 \%$ of turbidity (from $900 \mathrm{NTU}$ to $54 \mathrm{NTU}$ ) within 5 minutes after 30 minutes of flocculation.

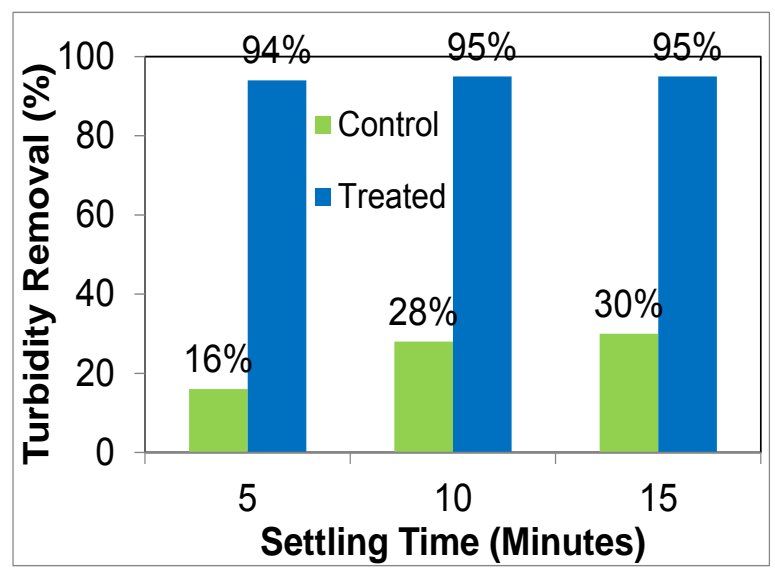

Fig. 5: Turbidity Removal using Fungal Coagulant

\section{B. Effects of Mixing Time}

Mixing is an important component of coagulation and flocculation process. Mixing during coagulation provides contacts among the particles and coagulating agents [14]. The flocculating performance of strain RWF-1 for a mixing period of 20 mins was slightly higher than that of 40 mins while the mixing rate was $120 \mathrm{rpm}$. Similarly, the performance of RWF3 for 30 mins was slightly higher than that of 40 mins for the same agitation speed. On the contrary, the current study found that the flocculating rates of strains RWF-5 and RWF-6 at mixing speed of $120 \mathrm{rpm}$ was higher for 40 minutes than those of $20 \mathrm{mins}$ and $30 \mathrm{mins}$. For longer coagulation and flocculation periods, the turbidity reduction rates increased from $91 \%$ to $95 \%$ by RWF-5 and $71 \%$ to $77 \%$ by RWF-6. These findings exhibited that high mixing time encourages more kaolin particles to aggregate than the other low speeds of 20 mins and 30 mins except for two strains, which were RWF1 and RWF-3.

\section{CONCLUSIONS}

The need of an environmentally friendly and cheap natural coagulant is well-felt for the water resources management. Therefore, discovery of an eco-friendly potential microbial coagulants is attempted in this study. Several types of fungi and yeasts were screened to identify the strains potential to be used as coagulant to reduce turbidity of water. Thus far, a potential fungal strain is successfully identified which could reduce turbidity of water from $900 \mathrm{NTU}$ to $54 \mathrm{NTU}$. It is expected that further optimization of the process parameters will help reduce the turbidity of the water.

\section{ACKNOWLEDGMENT}

The authors would like to express their gratitude to the Ministry of Education (MOE) Malaysia for granting the Fundamental Research Grant Scheme (FRGS-14-109-0350) for this project. Thanks also due to IIUM for continued supports in conducting research works.

\section{REFERENCES}

[1] Ebeling, J.M., Sibrell, P.L., Ogden, S.R., Summerfelt, S.T., 2003. Evaluation of chemical coagulation-flocculation aids for the removal of suspended solids and phosphorus from intensive recirculating aquaculture effluent discharge. Aquacultural Engineering, 29(1), 23-42. http://dx.doi.org/10.1016/S0144-8609(03)00029-3

[2] Salehizadeh, H., Shojaosadati, S.A., 2001. Extracellular biopolymeric flocculants: recent trends and biotechnological importance. Biotechnology Advances, 19(5), 371-385. http://dx.doi.org/10.1016/S0734-9750(01)00071-4

[3] Li, Z., Zhong S., Lei, H.Y., Chen, R.W., Yu, Q., Li, H.L., 2009. Production of a novel bioflocculant by Bacillus licheniformis X14 and its application to low temperature drinking water treatment. Bioresource Technology, 100(14), 3650-3656. http://dx.doi.org/10.1016/j.biortech.2009.02.029

[4] Sobeck, D.C., Higgins, M.J., 2002. Examination of three theories for mechanisms of cation-induced bioflocculation. Water Research, 36, 527-538. http://dx.doi.org/10.1016/S0043-1354(01)00254-8

[5] Bala, S., Yan, S., Tyagi, R.D., Surampalli, R.Y., 2008. A new, pelletforming fungal strain: its isolation, molecular identification, and performance for simultaneous sludge-solids reduction, flocculation, and dewatering. Water Environment Research, 80(9), 840-852. http://dx.doi.org/10.2175/106143008X304703

[6] Aljuboori, A.H.R., Uemura, Y., Osman, N.B., Yusup, S., 2014. Production of a bioflocculant from Aspergillus niger using palm oil mill effluent as carbon source. Bioresour. Technol. 171, 66-70. http://dx.doi.org/10.1016/j.biortech.2014.08.038

[7] Gross, R.A., Kalra, B., 2002. Biodegradable polymers for the environment. Science, 297 (5582), 803-807. http://dx.doi.org/10.1126/science.297.5582.803

[8] Zhao, H., Liu H., Zhou, J., 2013. Characterization of a bioflocculant MBF-5 by Klebsiella pneumoniae and its application in Acanthamoeba cysts removal. Bioresour. Technol. 137, 226-232. http://dx.doi.org/10.1016/j.biortech.2013.03.079

[9] Altaher, H., Alghamdi, A., 2011. Enhancement of quality of secondary industrial wastewater effluent by coagulation process: A case Study. Journal of Environmental Protection, 2(09), 1250-1256. http://dx.doi.org/10.4236/jep.2011.29144

[10] Sakthi, S.S., Kanchana, D., Saranraj P., Usharani G., 2012. Evaluation of Amylase Activity of the amylolytic Fungi Aspergillus niger using Cassava as Substrate. International Journal of Applied Microbiology Science, 1: 24-34.

[11] Pu, S.Y., Qin, L.L., Che, J.P., Zhang, B.R., Xu, M., 2014. Preparation and application of a novel bioflocculant by two strains of Rhizopus sp. using potato starch wastewater as nutrilite. Bioresource technology, 162, 184-191. http://dx.doi.org/10.1016/j.biortech.2014.03.124

[12] Aljuboori, A.H.R., Idris, A., Abdullah, N., Mohamad, R., 2013. Production and characterization of a bioflocculant produced by Aspergillus flavus. Bioresour. Technol. 127, 489-493. http://dx.doi.org/10.1016/j.biortech.2012.09.016

[13] Deng, S.B., Bai, R.B., Hu, X.M., Luo, Q., 2003. Characteristics of a bioflocculant produced by Bacillus mucilaginosus and its use in starch wastewater treatment. Appl. Microbiol. Biotechnol. 60, 588-593. http://dx.doi.org/10.1007/s00253-002-1159-5

[14] Chen, L.A., Serad, G.A., Carbonell, R.G., 1998. Effect of mixing conditions on flocculation kinetics of wastewaters containing proteins and other biological compounds using fibrous materials and polyelectrolytes. Braz. J. Chem. Eng. 15, 358-368. http://dx.doi.org/10.1590/S0104-66321998000400005 